\section{Severe polymyalgia-like symptoms secondary to anti-PD1 therapy successfully managed without discontinuing checkpoint inhibitor}

After reading the article from Braaten et al, ${ }^{1}$ we reinforce our idea that suspending checkpoint inhibitors (CPI) due to musculoskeletal symptoms, even if severe, may not always be a good alternative, since in addition to losing an option in the treatment of cancer we do not know if the symptoms will actually resolve with treatment interruption. Here we present a patient who developed severe polymyalgia rheumatic-like (PMR) symptoms 7 months after initiation of nivolumab for metastatic melanoma. Since it was a grade 3 immune-related adverse event according to the guidelines published in the Journal of Clinical Oncology, ${ }^{2}$ the oncologist initiated high-dose prednisone and opioids, considered interrupting the CPI, and requested rheumatology evaluation. After a shared discussion between the two specialties and the patient, considering his good life expectancy as well as the good tumour response to the drug, we decided to start methotrexate $15 \mathrm{mg}$ weekly without stopping the anti-programmed cell death protein 1 (PD1) therapy. Weeks after, the patient evolved with a significant improvement in symptoms, successfully weaning off prednisone and stopping nivolumab 12 months later, without identifying any clinically significant drug interactions. Unfortunately, corroborating Braaten et al's paper, ${ }^{1}$ PMR-like symptoms persisted in the patient, still demanding methotrexate 2 years after stopping the CPI.

This case illustrates a different approach from what is usually recommended by recent guidelines. ${ }^{23}$ Although several adverse rheumatological effects have already been described (eg, aggravation of degenerative conditions, drug-induced lupus, vasculitis and so on) ${ }^{4}$ with regard to musculoskeletal manifestations, the guidelines suggest that for severe PMR-like symptoms (eg, grades 3-4) immunotherapy should be suspended. ${ }^{2}$ Since we consider that this behaviour may not be the best for most patients with PMR-like or inflammatory arthritis, we wonder: should we stop the pain or stop the cancer ${ }^{5}$ ?

The authors believe that a good rheumatologist-oncologist relationship is essential before deciding to discontinue the CPI which has been fulfilling its role. ${ }^{5}$ We suggest that, as a rule, non-life-threatening symptoms such as joint pain are not enough for the oncologist to suspend immunotherapy, and it is up to us to keep patients comfortable with the CPI, while ensuring them good quality of life. The rationale for this lies in the widely known safety of conventional disease-modifying antirheumatic drugs (DMARD) (eg, methotrexate, sulfasalazine and hydroxychloroquine) in the doses practised by the rheumatologist; in a faster weaning of prednisone, minimising its undesired effects; and that stopping CPI therapy due to articular pain will not necessarily cease the rheumatic symptoms, but may carry the risk of cancer advancing. ${ }^{6}$

Thus, the individualisation of treatment is crucial, and until there are more studies concomitant use of CPI therapy with conventional DMARDs should be chased. It is possible to stop pain and cancer, ${ }^{7}$ and seeking this balance in real life is much more than following protocols and guidelines.

\section{Carlos Antonio Moura $\odot$, Carlos Geraldo Moura}

Internal Medicine and Rheumatology, Hospital Santo Antonio, Salvador, Bahia, Brazil

Correspondence to Dr Carlos Antonio Moura, Hospital Santo Antônio, Salvador, BA 40150360, Brazil; caggmoura@yahoo.com.br

Contributors Both authors contributed to the realisation of this article.

Funding The authors have not declared a specific grant for this research from any funding agency in the public, commercial or not-for-profit sectors.

Competing interests None declared.

Patient and public involvement Patients and/or the public were not involved in the design, or conduct, or reporting, or dissemination plans of this research.

Patient consent for publication Not required.

Provenance and peer review Not commissioned; internally peer reviewed.

(C) Author(s) (or their employer(s)) 2020. No commercial re-use. See rights and permissions. Published by BMJ.

\section{Check for updates}

To cite Moura CA, Moura CG. Ann Rheum Dis Epub ahead of print: [please include Day Month Year]. doi:10.1136/annrheumdis-2020-217605

Received 13 April 2020

Revised 20 April 2020

Accepted 22 April 2020

Ann Rheum Dis 2020;0:1. doi:10.1136/annrheumdis-2020-217605

\section{ORCID iD}

Carlos Antonio Moura http://orcid.org/0000-0003-1812-299X

\section{REFERENCES}

1 Braaten TJ, Brahmer JR, Forde PM, et al. Immune checkpoint inhibitor-induced inflammatory arthritis persists after immunotherapy cessation. Ann Rheum Dis 2020;79:332-8.

2 Brahmer JR, Lacchetti C, Schneider BJ, et al. Management of immune-related adverse events in patients treated with immune checkpoint inhibitor therapy: American Society of clinical oncology clinical practice guideline. J Clin Oncol 2018;36:1714-68.

3 Haanen JBAG, Carbonnel F, Robert C, et al. Management of toxicities from immunotherapy: ESMO clinical practice guidelines for diagnosis, treatment and followup. Ann Oncol 2017;28:iv119-42.

4 Abdel-Wahab N, Shah M, Lopez-Olivo MA, et al. Use of immune checkpoint inhibitors in the treatment of patients with cancer and preexisting autoimmune disease: a systematic review. Ann Intern Med 2018;168:121.

5 Moura CA, Moura CG. Checkpoint inhibitors and arthritis: seeking balance between victories and defeats. Ann Rheum Dis 2019;78:e91.

6 Calabrese C, Kirchner E, Kontzias A, et al. Rheumatic immune-related adverse events of checkpoint therapy for cancer: case series of a new nosological entity. RMD Open 2017;3:e000412.

7 Moura CA, Moura CG, Moura T. Rheumatologic symptoms and checkpoint inhibitor Stop pain or stop cancer? Semin Arthritis Rheum 2019:49:e8. 